\title{
Evaluating the Influence of Polymer Modified Asphalt Binders on Low Temperature Properties
}

\author{
Amal Abdelaziz ${ }^{1, *}$, Chun-Hsing $\mathrm{Ho}^{1}$, and Matthew Snyder ${ }^{1}$ \\ ${ }^{1}$ Northern Arizona University, 2112 S Huffer Ln, Flagstaff AZ 86011, USA
}

\begin{abstract}
Low temperature cracking is one of the most common distress types in asphalt concrete pavements, particularly in cold regions. Many factors influence the behaviour of asphalt concrete pavements at low temperatures, such as the applied traffic load, environmental conditions and material characteristics. Asphalt binders are one of the primary factors that influence material properties. The purpose of this study is to compare the performance of two types of asphalt binders: styrene-butadiene-styrene (SBS) modified asphalt binder and unmodified asphalt binder in resisting low temperature cracking. The study was conducted in Flagstaff, located at the area of Northern Arizona, in the United States. Asphalt samples were collected from the paving sections and were compacted and trimmed into small beams. Bending Beam Rheometer tests were performed, using the trimmed specimens at temperatures of $-6^{\circ} \mathrm{C},-12^{\circ} \mathrm{C}$ and $-18^{\circ} \mathrm{C}$. Based on the results of the study, it was concluded that, SBS modified asphalt binder performs better in resisting low temperature cracking, compared to the unmodified binder. Based on the study outcomes, it is recommended to use SBS polymer modified polymers in areas subjected to severe cold weather events to maximize the life span of asphalt concrete pavements.
\end{abstract}

\section{Introduction}

Low temperature cracking or thermally induced cracking of asphalt pavements is one of the most predominant distress types in cold regions, particularly in Canada and northern United States [1,2]. This problem leads to the early deterioration of asphalt concrete pavements, due to the inability of pavement to dissipate the stress from excessive thermal contraction [3]. Previous research showed that the addition of polymers to asphalt mixtures enhances its performance, by increasing the ability of pavement to resist thermal cracking, fatigue distress and rutting. Moreover, the addition of polymers has shown to improve the performance of asphalt binders by increasing the characteristics of elastic recovery, viscosity, cohesive strength and ductility [4]. The research on the behaviour of polymer modified bitumen can be found in extensive studies since the 90s. The concept of modifying virgin bitumen was based on increasing the viscoelastic range of virgin asphalt to improve its flexibilty at low temperatures [5].

Styrene-butadiene-styrene (SBS) polymer is one of the most common modifiers used in asphalt mixtures around the world. Most of the current research is focused on the impact of

\footnotetext{
*Corresponding author: aa2399@nau.edu
} 
SBS polymers on high temperature properties of asphalt mixtures. However, the factors affecting low temperature properties have not been well studied yet. Some of the previous research showed that SBS polymers could improve the low temperature cracking properties of asphalt mixtures. For example, a research done at Tongji University showed that the addition of SBS polymer reduces the stiffness of asphalt mixtures at low temperatures, indicating that SBS modifiers have a positive influence on the performance of asphalt pavements at low temperatures [6]. On the other hand, other research projects showed that the addition of SBS polymer does not have a significant impact on the stiffness of asphalt mixtures. For example, a research performed at Cooper Union University on evaluating the influence of the addition of SBS polymer, showed that modified SBS polymers are more prone to low temperature cracking, compared to unmodified asphalt binders [7]. Thus, due to the inconsistent research results, it is necessary to conduct further investigations to better understand the influence of SBS modified asphalt binders on low temperature cracking properties.

Currently, there are multiple testing methods that can be used to determine the low temperature properties of asphalt mixtures which include, the Indirect Tensile Test (IDT), the Thermal Stress Restraint Specimen Test (TSRST), and the Bending Beam Rheometer (BBR) test. The IDT method is a common test used in evaluating thermal cracking. The method is a combination of three tests which are, the static creep, resilient and modulus and strength tests [8]. While, the TRST method characterizes low temperature cracking taking into account the thermal and mechanical effects. The test is performed by maintaining a constant axial strain and as the temperature decreases, to allow the specimen to contract, while the servo-hydraulic press in the device prevents it. This process increases the thermal stress in the specimen until it fractures [9]. The Bending Beam Rheometer (BBR) test, also known as the standard test for binder at low temperatures, is a simple and cost-effective method used to determine the creep behaviour of asphalt mixtures. The results of BBR tests showed to be comparable to those of the IDT test [10]. The test measures the deflection of thin asphalt beams, at a constant load and constant temperature. The advantages of using BBR test over the other testing methods include, the equipment availability at reasonable costs and the reduced specimen size, as the beams tested in the BBR machine are only 12.5 x $6.75 \times 127 \mathrm{~mm}$ [11].

The purpose of this study is to provide a laboratory investigation method using BBR test, to study the impact of adding SBS polymer on the low temperature properties of asphalt mixtures. A paving project was implemented along the area of Northern Arizona, in the United States. Two types of asphalt mixtures were used in the project which are: unmodified asphalt binder and SBS modified binder. BBR tests were performed to determine the low temperature cracking properties of both asphalt binders. In addition, viscoelastic analysis was conducted to evaluate and compare the relaxation modulus of both asphalt binders. Based on the laboratory results and viscoelastic analysis, conclusions and recommendations for future research needs are provided.

\section{Methodology}

\subsection{Sample Preparation}

The study was completed using two types of asphalt mixtures: SBS polymer modified asphalt mixture and unmodified asphalt mixture. A PG 70-22 asphalt binder was used for both asphalt mixtures. A $3 / 4$ inches nominal material aggregate size was used for the unmodified and modified asphalt binders. The characteristics of the mix design used for asphalt mixtures are summarized in Table 1 . 
Table 1. Mix design characteristics.

\begin{tabular}{|l|l|l|}
\hline Mix Design & $\begin{array}{l}\text { Unmodified Asphalt } \\
\text { Binder (Non- SBS) }\end{array}$ & $\begin{array}{l}\text { Modified Binder } \\
(\text { SBS })\end{array}$ \\
\hline Nominal material aggregate size & $3 / 4$ inches & $3 / 4$ inches \\
\hline Asphalt binder type & PG 70-22 & PG 70-22 SBS \\
\hline Percent of asphalt binder $(\%)$ & 5.7 & 5.7 \\
\hline Bulk specific gravity $\left(\mathrm{G}_{\mathrm{mb}}\right)$ & 2.385 & 2.379 \\
\hline Maximum theoretical gravity $\left(\mathrm{G}_{\mathrm{mm}}\right)$ & 2.509 & 2.499 \\
\hline Percent of air void, $\%$ & 5 & 4.8 \\
\hline Voids in mineral aggregate filled (VMA), \% & 15.4 & 15.5 \\
\hline Percent of void filled $($ VFA), \% & 67.8 & 69 \\
\hline
\end{tabular}

To study the low temperature cracking properties, asphalt samples were collected from the paving project and got reheated and compacted at the Materials Laboratory of Arizona Department of Transportation (ADOT), using a Superpave gyratory compactor (SGC). Then, asphalt samples were cut into six faced blocks. After that, the asphalt blocks were trimmed into small specimens to get them prepared for BBR testing. The testing procedures used to perform BBR test are based on The American Association of State Highway and Transportation Officials (AASHTO) standard TP125: Determining the Flexural Creep Stiffness of Asphalt Mixtures Using the Bending Beam Rheometer (BBR) [12]. Figures 1 through 9 illustrate the process of obtaining the asphalt samples from the paving site until they were tested in the BBR machine.

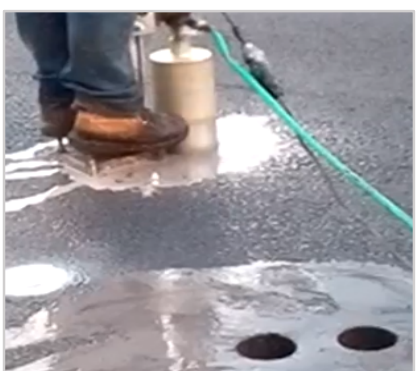

Fig. 1. Getting samples from site

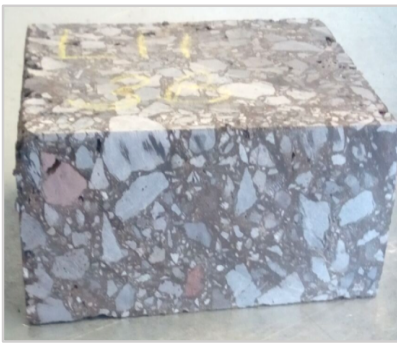

Fig. 4. Six faced asphalt block

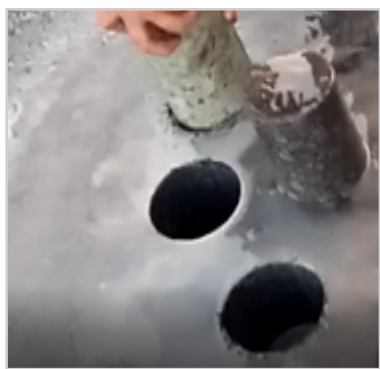

Fig. 2. Asphalt samples

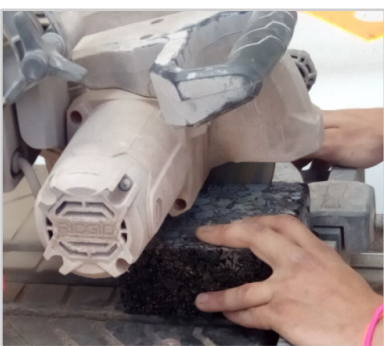

Fig. 5. Asphalt block trimming

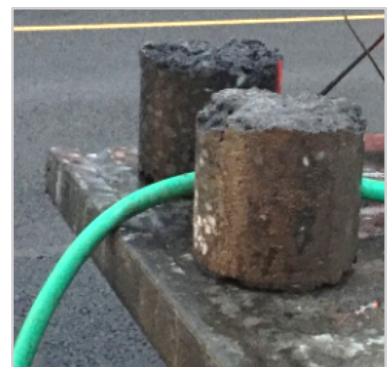

Fig. 3. Transporting samples to lab

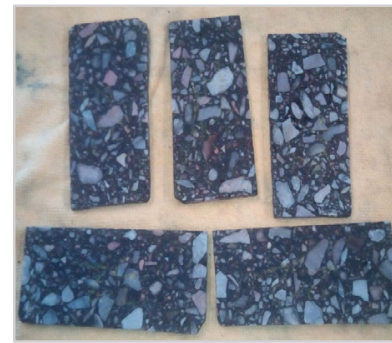

Fig. 6. Trimmed flat beams 


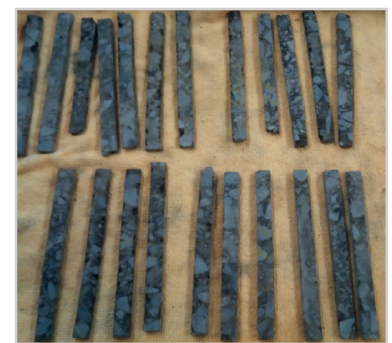

Fig. 7. Thin beams for BBR tests

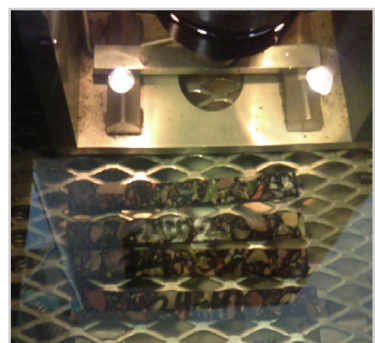

Fig. 8. Beams were conditioned in the bath of the BBR machine for 60 minutes

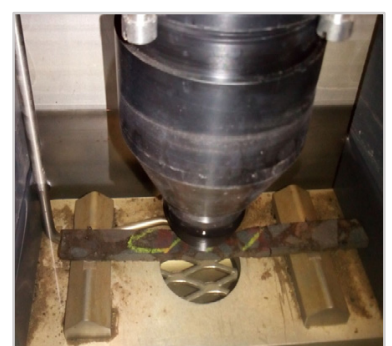

Fig. 9. BBR test

\subsection{Determination of Air Void Ratio}

Measuring the air void ratio of the asphalt blocks is necessary, to ensure that the air void ratio did not significantly change when the SGC samples were cut into six faced asphalt blocks. Moreover, inconsistency in the air void ratio could lead to misleading BBR test results. Air void ratios were calculated based on Equation (1):

$$
\% \text { air voids }=(1-\mathrm{D} / \mathrm{E}) * 100
$$

Where:

$\mathrm{D}=$ the bulk specific gravity; and

$\mathrm{E}=$ the maximum rice specific gravity.

The calculated air voids percentages for the asphalt blocks were approximately $2 \%$ to $3 \%$ less than the percent of air voids for the SGC asphalt samples. The consistent reduction in air voids among the different asphalt blocks, indicates that the effect of the change in air voids on BBR tests is negligible.

\subsection{Bending Beam Rheometer Tests}

Thin asphalt beams were tested in the BBR machine at three different temperatures: $-6^{\circ} \mathrm{C}$, $-12{ }^{\circ} \mathrm{C}$ and $-18{ }^{\circ} \mathrm{C}$, based on the used binder and in accordance with AASHTO T313 Standard [13]. A minimum of 5 beams from each asphalt mixture were used to run BBR tests at the desired temperatures $[14,15]$. The BBR test measure the deflection and the stiffness of the beams at time increments of 0.5 seconds. The linear viscoelastic stiffness modulus obtained from the BBR tests can be calculated using Equation (2):

$$
\mathrm{S}(\mathrm{t})=\mathrm{PL}^{3} / 4 \mathrm{bh}{ }^{3} \delta(\mathrm{t})
$$

Where:

$\mathrm{S}(\mathrm{t})=$ the creep stiffness as a function of time in MPa;

$\mathrm{P}=$ constant applied load in $\mathrm{N}$;

$\mathrm{L}=$ span length in $\mathrm{mm}$;

$\mathrm{b}=$ beam width in $\mathrm{mm}$;

$\mathrm{h}=$ beam thickness in $\mathrm{mm}$; and

$\delta(t)=$ beam deflection in $\mathrm{mm}$.

The measured stiffness values using BBR tests for both asphalt mixtures at a time of 60 seconds are summarized in Table 2. As illustrated Figure 10, the average elastic modulus values of the unmodified asphalt binder are higher than the SBS modified binder, indicating that unmodified binders have higher stiffness and strength compared to the modified asphalt 
binder. Determining the stiffness or the elastic modulus of asphalt mixtures is critical, as a reduction in the stiffness, increases the critical strains exerted on pavement, as a result making the pavement more prone to surface deformation [16]. In addition, it can be noted that all of the calculated coefficients of variances are below $20 \%$, indicating low variability among the different beams [17].

Table 2. Statistical information on the stiffness of asphalt mixtures

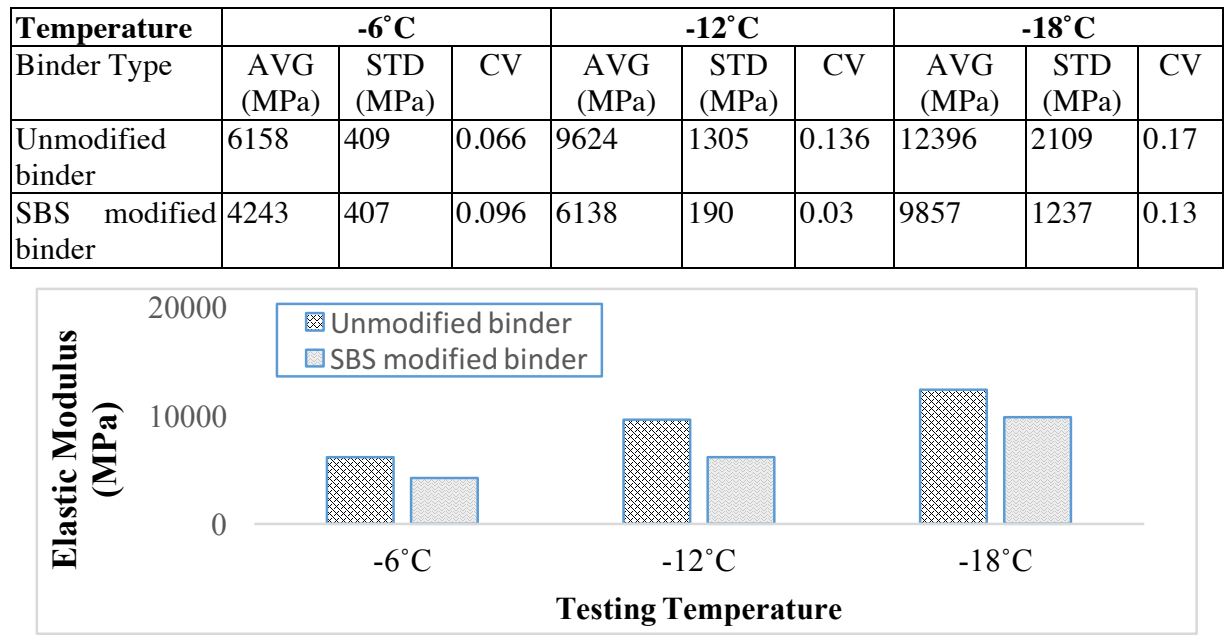

Fig. 10. Elastic Modulus at 60 seconds for non-SBS and SBS mixtures

\section{Results and Discussion}

Viscoelastic analysis was performed to determine creep compliance values of the unmodified asphalt binder and SBS modified binder at the three different temperatures: $-6^{\circ} \mathrm{C},-12{ }^{\circ} \mathrm{C}$ and $-18{ }^{\circ} \mathrm{C}$. The time-temperature superposition principle (TTSP) was used to shift the creep compliance curves at the three temperatures for both asphalt mixtures, as shown in Figures 11 through 14. The shift factor used in the adopted TTSP model of the was calculated using an exponential function of time. The viscoelastic analysis showed that SBS modified asphalt binder has higher creep compliance values compared to the unmodified binder.

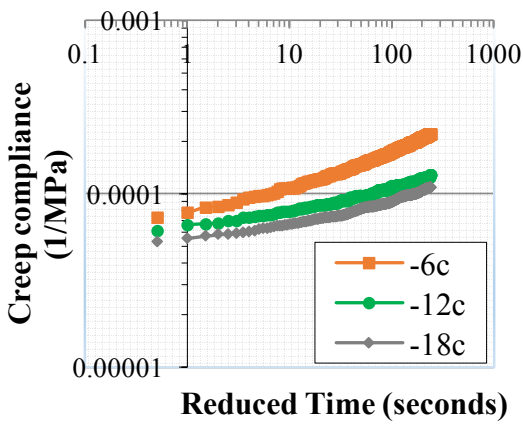

Fig. 11. Creep Compliance Curves (Non-SBS)

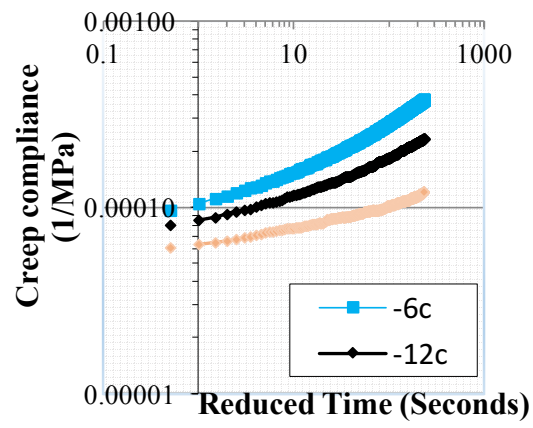

Fig. 12. Creep Compliance Curves (SBS) 


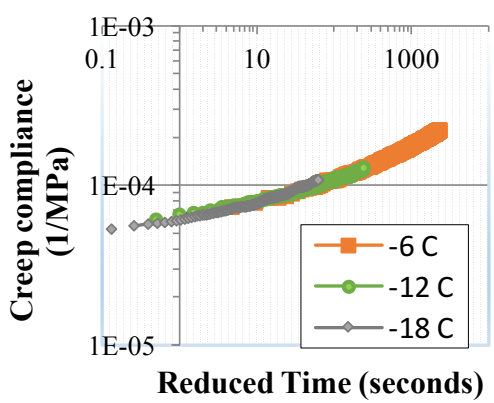

Fig. 13. Master Curve (Non-SBS)

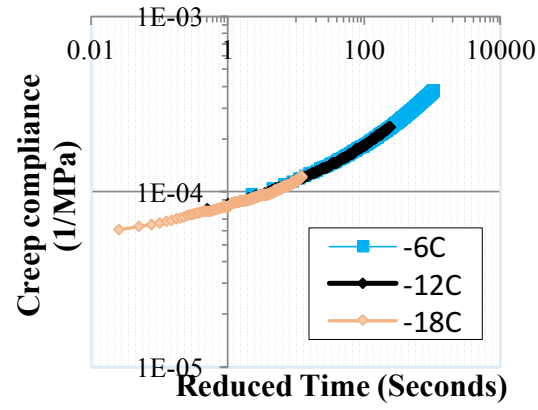

Fig. 14. Master Curve (SBS)

The power law function, provided in Equation (3), was used to generate a fitting curve for the master curves of both asphalt mixtures, as shown in Figures 15 and 16. A reference temperature of $-12^{\circ} \mathrm{C}$ was used. The parameters of the power function: were determined using the fitting curves, and are summarized in Table 3.

$$
\mathrm{D}(\mathrm{t})=\mathrm{D}_{0}+\mathrm{D}_{1} \mathrm{t}^{\mathrm{n}}
$$

Where:

$\mathrm{D}(\mathrm{t})=$ creep compliance values in $1 / \mathrm{MPa}$ at reduced time;

$\mathrm{t}=$ reduced time in seconds; and

$\mathrm{D}_{0}, \mathrm{D}_{1}$ and $\mathrm{n}$ are power law parameters.

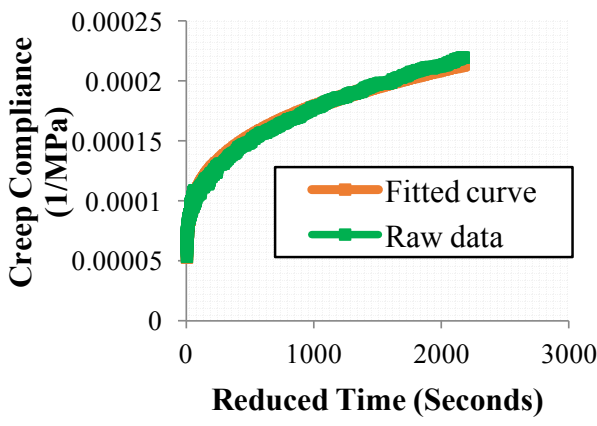

Fig. 15. Power Law funtion (non-SBS)

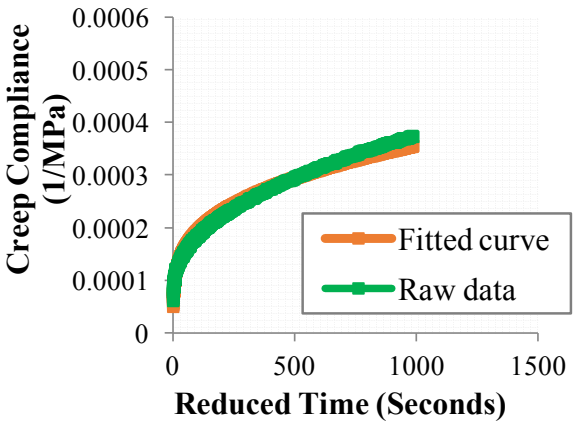

Fig. 16. Power Law funtion (SBS)

Table 3. Power law function parameters

\begin{tabular}{|l|l|l|l|}
\hline Asphalt Binder & $\mathbf{D}_{\mathbf{0}}(\mathbf{1} / \mathbf{M P a})$ & $\mathbf{D}_{\mathbf{1}}(\mathbf{1} / \mathbf{M P a})$ & $\mathbf{n}$ \\
\hline $\begin{array}{l}\text { Unmodfied asphalt } \\
\text { binder }\end{array}$ & $4.3461 \mathrm{E}-05$ & $1.69881 \mathrm{E}-05$ & 0.299999998 \\
\hline $\begin{array}{l}\text { SBS modified } \\
\text { binder }\end{array}$ & $3.8132 \mathrm{E}-05$ & $3.7428 \mathrm{E}-05$ & 0.310000515 \\
\hline
\end{tabular}

The relaxation modulus of the unmodified binder and the SBS modified binder are provided in Figure 17. The SBS modified asphalt binder showed to have higher relaxation capabilities compared to the unmodified binder. Thus, indicating that the SBS asphalt mixture have better abilities in relaxing thermal induced stress, compared to the unmodified binder, as it showed to have better relaxation properties. 


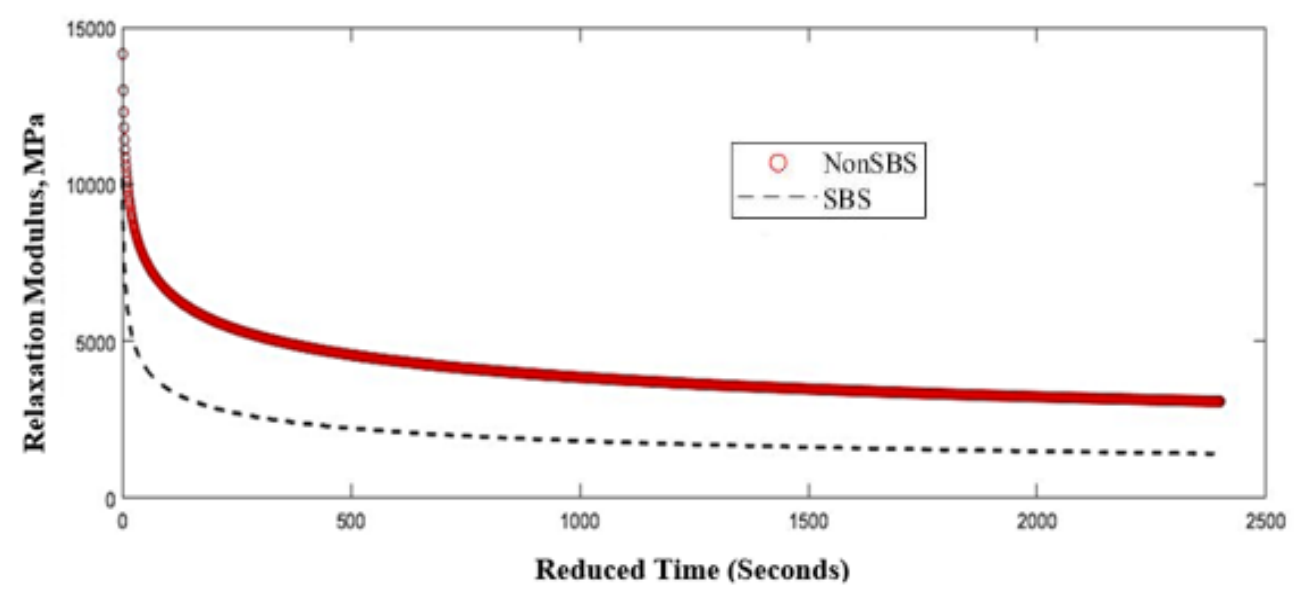

Fig. 17. Relaxation modulus curves.

\section{Conclusions and Recommendations}

In this study the influence of adding SBS polymer on the low temperature properties of asphalt mixtures was investigated. The study was completed by comparing the thermal cracking properties of unmodified asphalt mixtures and SBS modified mixture, through laboratory tests and viscoelastic analysis. Based on the outcomes of the study the following can be concluded:

- The Bending Beam Rheometer (BBR) test is capable of evaluating low temperature properties of asphalt mixtures efficiently, with a minimum variability among different asphalt beams.

- The unmodified asphalt binder showed to have higher stiffness values compared to the SBS modified binder at the three testing temperatures: $-6{ }^{\circ} \mathrm{C},-12{ }^{\circ} \mathrm{C}$ and $-18^{\circ} \mathrm{C}$.

- The relaxation capabilities of the SBS modified asphalt binder were higher than the unmodified binder, indicating that the SBS modified binder has better abilities in resisting induced thermal stress.

- The addition of SBS modifier to asphalt binder lead to an improvement in low temperature cracking properties of asphalt mixtures.

- Field visits need to be done to further verify the results obtained from laboratory methods and viscoelastic analysis.

\section{References}

1. M.O. Marasteanu, X. Li, T.R. Clyne, V. Voller, D.H. Timm, D. Newcomb, Low Temperature Cracking of Asphalt Concrete Pavement (2004)

2. X-J. Li, M. O. Marasteanu, Experimental Mechanics 50(7), 867-876 (2010)

3. J. Liu, S. Zhao, L. Li, P. Li, S. Saboundjian, Cold Regions Science and Technology 141, 78-85 (2017)

4. Y. Yildirim, Construction and Building Materials 21(1), 66-72 (2007)

5. K.R. Wardlaw, S. Shuler, Polymer modified asphalt binders (1992)

6. P. Lin, W. Huang, Y. Li, N. Tang, F. Xiao, Constr. Build. Mater. 154, 609-622 (2017)

7. K.W. Ng, Masters Abstracts Int. 46, 6 (2008) 
8. P.K. Das, Y. Tasdemir, B. Birgisson, Constr. Build. Mater. 30, 643-649 (2012)

9. N. Tapsoba, H. Baaj, C. Sauzéat, H.D. Benedetto, M. Ech, Constr. Build. Mater. 120, 393-402 (2016)

10. X. Gong, P. Romero, Z. Dong, Y. Li. Constr. Build. Mater. 156, 56-62 (2017)

11. P. Romero. Using the bending beam rheometer for low temperature testing of asphalt mixtures (2016)

12. AASHTO TP125 (2016)

13. AASHTO T313 (2008)

14. P. Romero, C.H. Ho, K. VanFrank, Development of Methods to Control Cold Temperature and Fatigue Cracking for Asphalt Mixtures (2011)

15. CH. Ho, P. Romero, Road materials and pavement design 12(2), 293-314 (2011)

16. X. Hu, A.N. Faruk, J. Zhang, M.I. Souliman, L.F. Walubita, Int. J. Pavement Res. Techn. (2017)

17. N. Nielsen, B. Hauser, T. Preber, P. Sebaaly, D. Johnston, D. Huft, S. Bang, L. Roberts. Quality Base Material Produced Using Full Depth Reclamation on Existing Asphalt Pavement Structure (2007) 